\title{
KNOWLEDGE, ATTITUDE AND PRACTICE OF FOOD HANDLERS TOWARDS FOOD SAFETY
}

\author{
By \\ Al-Wehedy $\mathrm{A}^{1}$, Faisal $\mathrm{S}^{1}$, Omar $\mathrm{N}^{2}$ and Elsherbeny $\mathrm{E}^{1}$ \\ ${ }^{1}$ Department of Industrial Medicine and Occupational Health, ${ }^{2}$ Department of Medical Microbiology and \\ Immunology, Faculty of Medicine, Mansoura University. \\ Corresponding Author's: ElsherbenyE: email: Enass75@mans.edu.eg
}

Submit Date: 2020-08-13

Revise Date: $2020-08-26$

Accept Date: $2020-08-28$

DOI: $10.21608 /$ ejom.2020.34330.1205

Authors' contribution: Authors contributed equally to this work.

\begin{abstract}
Introduction: Food handlers play an important role in ensuring food safety throughout the chain of production, processing, storage and preparation of food. Good knowledge, positive attitude and good practice of food handlers are important for prevention of food borne diseases. Aim of work: To assess knowledge, attitude and practice (KAP) of food handlers towards food safety at Mansoura University Hospitals and find out personal and work-related factors associated with different KAP levels. Materials and Methods: A descriptive observational cross-sectional study was conducted from December 2016 to September 2017. It included all food handlers working at Mansoura University hospitals' kitchens who were on duty and fulfilling legibility criteria. The data were collected using a questionnaire about demographic data, occupational history, food safety knowledge and attitude. Observational checklist was used to assess the workers practice. Results: Only one quarter of food handlers had good knowledge towards food safety and hygiene, on contrary, most of them had a good attitude level $(61.0 \%)$ and a good hygienic practice level (59.0\%). High KAP scores were noted among females and university certified workers. The highest KAP scores were noted among veterinarians and cooks. There is a significant strong positive correlation between knowledge and attitude $(\mathrm{r}=0.78)$, and moderate positive correlation between knowledge and practice $(r=0.46)$. Conclusion: Limited number of food handlers had enough knowledge regarding food safety. Practice had a positive correlation with both knowledge and attitude. KAP scores of food handlers differ significantly regarding gender, educational level and type of work. It should be mandatory for food handlers to undergo a supervised food safety training courses prior to renewal of their license to ensure their efficacy.

Keywords: Attitude, Food handlers, Food hygiene, Knowledge and Practice.
\end{abstract}




\section{Introduction}

Food handler is defined as "any person" employed in the food premises and involved in the preparation, serving, washing or packing of food" (Young et al., 2019). Food handlers constitute an important occupational group in the health care sector because of the vital service they provide for patients and residents (Niles, 2019).

Food handlers play an important role in ensuring food safety. This responsibility is greater in hospitals, as patients are susceptible to nosocomial infections through food contamination by pathogenic organisms (Furst and Francis, 2018). Neglecting food safety measures in hospitals can lead to increased patients' morbidity and mortality (Askarian et al., 2004). Knowledge, attitude and practice (KAP) studies related to food safety examine and evaluate the participants' knowledge, opinion and behavior towards food safety issues; taking into consideration important determinants for food borne diseases (FBD) and different sources of food providing services (Hamadan and Almhaifer, 2015). Other studies postulated that positive KAP of the food handlers are key factors in preventing the occurrence of food borne diseases (FBDs) (Lazou et al., 2012 and Arendt et al., 2013).

All workers involved in handling food should have adequate knowledge about the four critical food safety factors; (FBDs, cross contamination, temperature control and personal health and hygiene) (Thelwell-Reid, 2014). Positive attitude is a necessary factor for translation of knowledge into appropriate practice (Zanin et al., 2017). Inappropriate handling practices can cause food contamination and FBD consequently, impairing the health of the consumer (Ercan and Kiziltan, 2014). Thus, a generally used tool to ensure the hygienic-sanitary quality is the application of KAP model (Baş et al., 2006). The assessment of practices can be performed using questionnaires; called self-reported practice or using work observation called the observed practices (Zanin et al., 2017).

Numerous literatures have identified knowledge, attitude and practice of food handlers towards food hygiene and safety within the community. Up to our knowledge, limited studies were conducted among food handlers at hospitals for referencing in Egypt. 


\section{Aim of work}

To assess knowledge, attitude and practice (KAP) of food handlers towards food safety at university hospitals and find out personal and work-related factors associated with different KAP levels.

\section{Materials and Methods}

Study design: A descriptive observational cross-sectional study.

Place and duration of the study: This study was conducted from December 2016 to September 2017 at Mansoura university hospitals' kitchens. The study recruited six hospitals; Mansoura University Hospital, Specialized Medical Hospital, Emergency Hospital, Ophthalmic Center, Mansoura University Child Hospital, Oncology Center Mansoura University.

Study sample: All working personnel dealing with food preparation and packing in Mansoura University Hospitals' kitchens were enrolled; 209 out of 227 were on duty at the time of the study and agreed to participate.

\section{Study methods:}

A) An interviewer-administrated questionnaire was divided into three sections. First section: was developed to obtain information about demographic characteristics of the participants. Second section: consisted of 15 questions to cover the knowledge about food safety and hygiene, based on the previous validated questionnaire by Fadaei (2015). The answers were (Yes/ NO) format. A score of 1 was given to the correct answer and 0 to the incorrect one with total score of knowledge ranging between $(0-15)$. The score was then converted to percentage and categorized into (a) Poor knowledge (less than and equal to 50\%), (b) Fair knowledge (51 to 69\%) and (c) Good knowledge (70\% and above) (Isara et al., 2013 and Rohin et al., 2016). Third section: included 10 statements evaluating food safety attitude, based on previous researches by (Baş et al., 2006 and Tokuç et al., 2009). The answers were graded on three-point Likert scale $(2=$ agree, $1=$ uncertain and, 0 $=$ disagree) with total score of attitude ranging between $(0-20)$. The score was then converted to percentage and categorized into (a) Poor attitude (less than and equal to 50\%), (b) Fair attitude (51 to 69\%) and (c) Good attitude (70\% and above) (Isara et al., 2013 and Rohin et al., 2016). The questionnaire was pilot tested in 25 respondents to check 
clarity of the questionnaire and estimate time needed to complete it, and then minor modifications were made.

B) An observational checklist for food safety practice; was filled for two hours throughout every working day. Observation was done at the prepreparation, preparation and package stations for approximately 90 hours. No instructions were given to the food handlers to nullify bias. The checklist was based on previous researches (Codex Alimentarius Commision, 2013, FDA, 2013 \& Ercan and Kiziltan, 2014) to evaluate hygienic practices of food handlers and consisted of 25 observations referred to main hygienic practices with total score of hygienic practice ranging between $(0-25)$. It was then converted to percentage and categorized into poor, fair and good (Rohin et al., 2016).-

\section{Consent}

Authors declared that an informed written consent was taken from the studied group, confidentiality was maintained.

\section{Ethical approval}

Before conducting the full-scale study, the protocol was approved by Mansoura Faculty of Medicine Institutional Research Board (MFMIRB); Code: MS/16.07.03. Written administrative permissions have been obtained from concerned authorities.

\section{Data management}

Data were coded, computed then analyzed using IBM SPSS version 24 for Windows . Descriptive statistics for qualitative variables were presented as number and percentage. While quantitative variables were presented as mean \pm standard deviation (SD) for normally distributed. Association between normally distributed continuous variables was tested using independent sample t-test and ANOVA. Pearson correlation was used to correlate continuous normally distributed data while Spearman correlation was used to correlate ordinal and non-normally distributed data. The difference was considered significant at $(p \leq 0.05)$ 


\section{Results}

Table 1: Socio-demographic and work-related characters of food handlers $($ No=209).

\begin{tabular}{|c|c|c|}
\hline Characters & Items & No $(\%)$ \\
\hline Age (years) & $($ Mean \pm SD) & $38.9 \pm 7.4$ \\
\hline Sex & $\begin{array}{l}>\text { Male } \\
>\text { Female }\end{array}$ & $\begin{array}{c}134(64.1 \%) \\
75(35.9 \%)\end{array}$ \\
\hline Education & $\begin{array}{l}>\text { Basic or less } \\
>\text { Secondary } \\
>\text { University }\end{array}$ & $\begin{array}{l}54(25.8 \%) \\
97(46.4 \%) \\
58(27.8 \%) \\
\end{array}$ \\
\hline Residence & $\begin{array}{l}>\text { Rural } \\
>\text { Urban }\end{array}$ & $\begin{array}{c}164(78.5 \%) \\
45(21.5 \%)\end{array}$ \\
\hline Contract type & $\begin{array}{l}>\text { Permanent } \\
>\text { Temporary }\end{array}$ & $\begin{array}{c}171(81.8 \%) \\
38(18.2 \%)\end{array}$ \\
\hline Food handling license & \multicolumn{2}{|c|}{$198(94.7 \%)$} \\
\hline Work shift & $\begin{array}{l}>\text { Morning } \\
>\text { Evening } \\
>\text { Night } \\
>\text { Rotating }\end{array}$ & $\begin{array}{c}134(64.1 \%) \\
8(3.8 \%) \\
4(1.9 \%) \\
63(30.1 \%) \\
\end{array}$ \\
\hline Periodic examination & $\begin{array}{l}>\text { Every } 6 \text { months } \\
>\text { Every } 1 \text { year } \\
>\text { Every } 2 \text { years }\end{array}$ & $\begin{array}{c}124(59.4 \%) \\
64(30.6 \%) \\
21(10.0 \%) \\
\end{array}$ \\
\hline Vaccines & $\begin{array}{l}>\text { No HAV or TAB\#\#\# } \\
>\text { HAV\# } \\
>\text { HBV\#\# }\end{array}$ & $\begin{array}{c}123(58.9 \%) \\
13(6.2 \%) \\
73(34.9 \%) \\
\end{array}$ \\
\hline Food training courses & \multicolumn{2}{|l|}{$52(24.9 \%)$} \\
\hline Current smoker & \multicolumn{2}{|l|}{$55(26.3 \%)$} \\
\hline
\end{tabular}

\# : Hepatitis A vaccine once 12 years ago. \#\#: All were partially vaccinated (didn't complete 3 doses of Hepatitis B vaccine). \#\#\#: Not received hepatitis A or typhoid vaccine.

The study included 209 middle aged food handlers working at six of Mansoura University hospitals' kitchens. More than half were male who received secondary education. Most of the participants had food handling license while all of food handlers had undergone a pre-employment medical examination. While periodic 
examination was performed every 6 months for more than half of them and annual examination for about one third of total participants. One third was given the first two doses of HBV vaccine at time of the study.

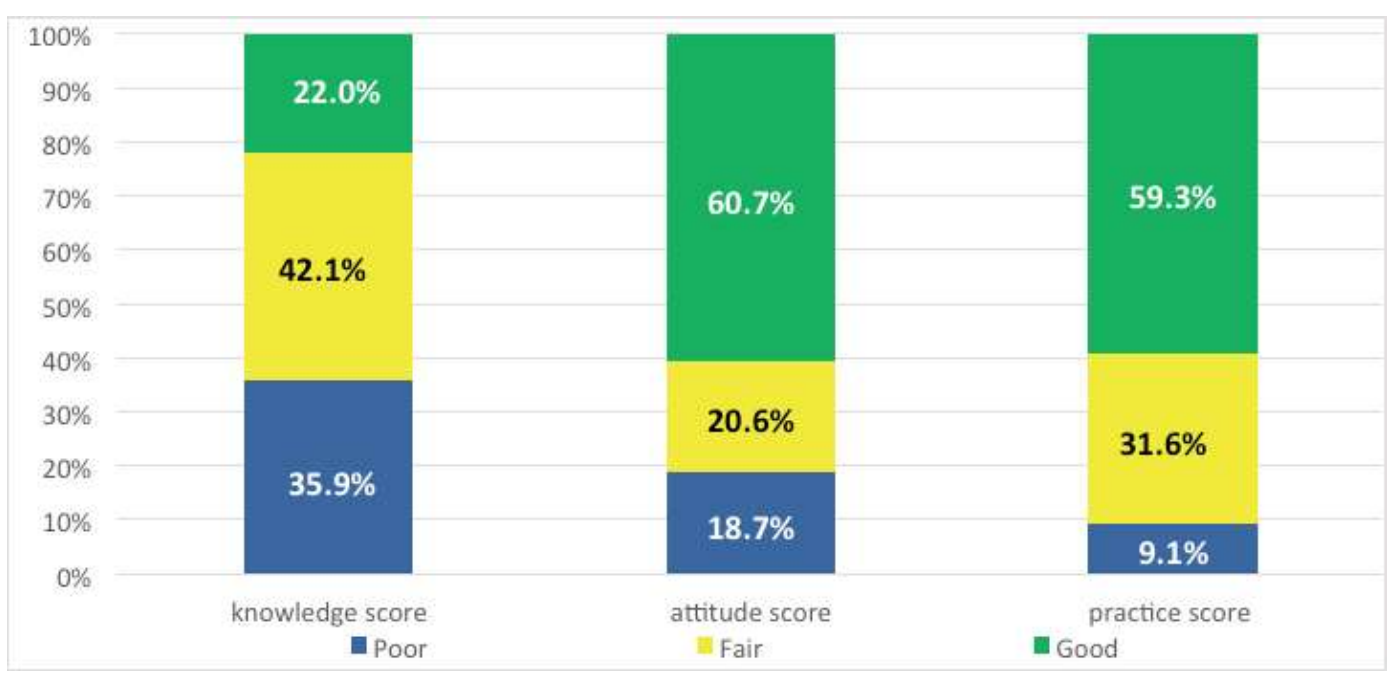

Figure1: Levels of food handlers' knowledge, attitude and hygienic practice.

According to (KAP) levels, about one third of food handlers have poor knowledge level while $42.0 \%$ had a fair level and only $22.0 \%$ had a good knowledge level. On contrary, more than half had a good attitude level and a good hygienic practice level. 
Table 2: Association between KAP scores and personal parameters of food handlers $(\mathbf{N o}=\mathbf{2 0 9})$

\begin{tabular}{|c|c|c|c|c|}
\hline Items & No & $\begin{array}{l}\text { Knowledge } \\
\text { score } \\
\text { Mean } \pm \text { SD }\end{array}$ & $\begin{array}{l}\text { Attitude score } \\
\text { Mean } \pm \text { SD }\end{array}$ & $\begin{array}{l}\text { Hygienic practice score } \\
\text { Mean } \pm \text { SD }\end{array}$ \\
\hline $\begin{array}{l}\text { Age groups } \\
>\quad 18- \\
>\quad 35- \\
>\quad 45-59 \text { years }\end{array}$ & $\begin{array}{c}59 \\
103 \\
47\end{array}$ & $\begin{array}{l}8.5 \pm 2.7 \\
8.2 \pm 2.8 \\
8.6 \pm 2.6\end{array}$ & $\begin{array}{l}15.3 \pm 1.8 \\
15.1 \pm 1.9 \\
15.0 \pm 1.8\end{array}$ & $\begin{array}{l}19.3 \pm 3.5 \\
18.8 \pm 4.2 \\
19.8 \pm 3.7\end{array}$ \\
\hline $\begin{array}{l}\text { One-Way ANOVA } \\
\mathrm{p} \text { value }\end{array}$ & & $\begin{array}{l}F=0.43 \\
(p \leq 0.65)\end{array}$ & $\begin{array}{l}F=0.13 \\
(p \leq 0.88)\end{array}$ & $\begin{array}{l}F=1.23 \\
(p=0.07)\end{array}$ \\
\hline $\begin{array}{l}\text { Gender } \\
>\quad \text { Males } \\
>\quad \text { Females }\end{array}$ & $\begin{array}{c}164 \\
45\end{array}$ & $\begin{array}{l}8.01 \pm 2.5 \\
9.9 \pm 3.04\end{array}$ & $\begin{array}{l}14.8 \pm 1.9 \\
16.1 \pm 1.6\end{array}$ & $\begin{array}{c}19.02 \pm 4.1 \\
21.2 \pm 2.9\end{array}$ \\
\hline $\begin{array}{l}\text { Student t-test } \\
\mathrm{p} \text { value }\end{array}$ & & $\begin{array}{c}t=4.3 \\
(p \leq 0.001)^{* * *}\end{array}$ & $\begin{array}{c}t=2.1 \\
(p=0.04)^{*}\end{array}$ & $\begin{array}{c}t=3.3 \\
(p=0.001)^{* * *}\end{array}$ \\
\hline $\begin{array}{l}\text { Residence } \\
>\quad \text { Rural } \\
>\quad \text { Urban }\end{array}$ & $\begin{array}{c}134 \\
75\end{array}$ & $\begin{array}{l}8.8 \pm 2.5 \\
7.8 \pm 2.9\end{array}$ & $\begin{array}{l}15.9 \pm 1.4 \\
13.6 \pm 2.2\end{array}$ & $\begin{array}{l}19.5 \pm 4.3 \\
19.4 \pm 3.2\end{array}$ \\
\hline $\begin{array}{l}\text { Student t-test } \\
\mathrm{p} \text { value }\end{array}$ & & $\begin{array}{c}t=2.6 \\
(p=0.009)^{* *}\end{array}$ & $\begin{array}{c}t=4.4 \\
(p \leq 0.001)^{* * *}\end{array}$ & $\begin{array}{c}t=0.1 \\
(p=0.92)\end{array}$ \\
\hline $\begin{array}{l}\text { Educational } \\
\text { level } \\
>\quad \text { Basic and } \\
\quad \text { less } \\
>\quad \text { Secondary } \\
>\quad \text { University }\end{array}$ & $\begin{array}{l}54 \\
97 \\
58\end{array}$ & $\begin{array}{c}7.1 \pm 2.8 \\
7.7 \pm 1.9 \\
10.9 \pm 2.3\end{array}$ & $\begin{array}{l}12.8 \pm 2.9 \\
14.9 \pm 1.1 \\
17.5 \pm 1.7\end{array}$ & $\begin{array}{c}18.6 \pm 4.3 \\
19.2 \pm 4.01 \\
20.9 \pm 3.1\end{array}$ \\
\hline $\begin{array}{l}\text { One-Way ANOVA } \\
\text { p value }\end{array}$ & & $\begin{array}{c}F=50.6 \\
(p \leq 0.001) * * *\end{array}$ & $\begin{array}{c}\mathbf{F}=27.1 \\
(\mathbf{p} \leq \mathbf{0 . 0 0 1 )} * * *\end{array}$ & $\begin{array}{c}\mathbf{F}=5.5 \\
(p=0.005) * *\end{array}$ \\
\hline
\end{tabular}

$*$ : Significant at $(\mathrm{p} \leq 0.05) . \quad * *$ : Significant at $(\mathrm{p} \leq 0.01) . \quad * * *$ : Significant at $(\mathrm{p} \leq 0.001)$.

There was a statistically significant difference when comparing mean KAP scores among participants, with higher scores among females and university certified workers. Rural food handlers were more knowledgeable, had positive attitude towards food safety compared to urban food handlers, with statistically significant difference. 
Table 3 : Association between KAP scores and work-related parameters (No=209)

\begin{tabular}{|c|c|c|c|c|}
\hline \multicolumn{2}{|c|}{ Items } & $\begin{array}{c}\text { Knowledge score } \\
\text { Mean } \pm \text { SD } \\
\end{array}$ & $\begin{array}{c}\text { Attitude score } \\
\text { Mean } \pm \text { SD } \\
\end{array}$ & $\begin{array}{l}\text { Hygienic practice } \\
\text { score Mean } \pm \text { SD }\end{array}$ \\
\hline \multicolumn{2}{|l|}{ 1- Type of work } & & & \\
\hline \multicolumn{2}{|l|}{ Cooks $(\mathrm{No}=31)$} & $10.5 \pm 1.2$ & $18.5 \pm 1.3$ & $22.1 \pm 1.5$ \\
\hline \multicolumn{2}{|l|}{ Bakers $(\mathrm{No}=9)$} & $7.4 \pm 1.4$ & $14.6 \pm 0.8$ & $13 \pm 2.3$ \\
\hline \multicolumn{2}{|c|}{ Veterinarians $(\mathrm{No}=8)$} & $14.4 \pm 0.7$ & $19.8 \pm 0.2$ & $22.6 \pm 0.7$ \\
\hline \multicolumn{2}{|l|}{ Observers $(\mathrm{No}=5)$} & $11.0 \pm 2.2$ & $18.4 \pm 0.5$ & $20 \pm 2$ \\
\hline \multicolumn{2}{|c|}{ - Clean workers $(\mathrm{No}=43)$} & $4.8 \pm 1.2$ & $8.4 \pm 1.6$ & $18.7 \pm 3.5$ \\
\hline \multicolumn{2}{|c|}{ Store workers $(\mathrm{No}=18)$} & $8.2 \pm 2.1$ & $17.8 \pm 1.2$ & $16.4 \pm 5.3$ \\
\hline \multicolumn{2}{|c|}{ - Nutrition specialists $(\mathrm{No}=20)$} & $11.7 \pm 0.8$ & $17.2 \pm 1.1$ & $20.4 \pm 2.5$ \\
\hline \multicolumn{2}{|c|}{ - Preparation Workers $(\mathrm{No}=71)$} & $8.2 \pm 1.2$ & $15.5 \pm 0.9$ & $19.2 \pm 3.6$ \\
\hline \multicolumn{2}{|c|}{ - Food service managers $(\mathrm{No}=4)$} & $11.1 \pm 1.4$ & $17.7 \pm 1.3$ & $20.5 \pm 1.3$ \\
\hline \multicolumn{2}{|l|}{$\begin{array}{l}\text { One-Way ANOVA } \\
\text { p value }\end{array}$} & $\begin{array}{c}F=76.2 \\
(p \leq 0.001)^{* * *}\end{array}$ & $\begin{array}{c}\mathrm{F}=43.4 \\
(\mathrm{p} \leq 0.001)^{* * * *}\end{array}$ & $\begin{array}{c}F=14.1 \\
(p \leq 0.001)^{* * *}\end{array}$ \\
\hline \multicolumn{2}{|l|}{ 2- Training courses } & & & \\
\hline Present & 52 & $8.8 \pm 2.8$ & $15.3 \pm 3.7$ & $20.5 \pm 3.3$ \\
\hline Absent & 157 & $8.3 \pm 2.7$ & $15.04 \pm 3.8$ & $19.1 \pm 4.1$ \\
\hline \multicolumn{2}{|l|}{$\begin{array}{l}\text { Student t-test } \\
\mathrm{p} \text { value }\end{array}$} & $\begin{array}{c}t=1.07 \\
(p=0.28)\end{array}$ & $\begin{array}{c}t=0.34 \\
(p=0.43)\end{array}$ & $\begin{array}{c}t=2.27 \\
(p=0.015)^{*}\end{array}$ \\
\hline
\end{tabular}

*: Statistically significant at $(\mathrm{p} \leq 0.05)$.

**: Statistically significant at $(\mathrm{p} \leq 0.01)$.

$* * *$ : Statistically significant at $(\mathrm{p} \leq 0.001)$

There was a statistically significant association between KAP scores and type of work of the food handlers with $p$-value $\leq 0.001$ in knowledge, attitude and hygienic practice. The highest knowledge score was recorded among veterinarians followed by nutrition specialists and finally food service managers. While the highest attitude score was noted among veterinarians then cooks and observers. Furthermore, the highest hygienic practice score was observed among veterinarians then cooks and food service managers. There was no significant difference in knowledge or attitude scores between food handlers who attended food safety training courses and those 
who did not. Contrary to hygienic practice score between food handlers who attended food safety training courses and those who did not, showed significant difference.

Table 4: Correlation between KAPscores and socio-demographic characteristics of food handlers.

\begin{tabular}{|l|c|c|c|}
\hline \multirow{2}{*}{ Parameters } & Knowledge & Attitude & Practice \\
\cline { 2 - 4 } & $\mathbf{r}$ & $\mathbf{r}$ & $\mathbf{r}$ \\
\hline Age & 0.05 & -0.04 & -0.06 \\
\hline Educational level & $\mathbf{0 . 5 3 ^ { * * }}$ & $\mathbf{0 . 4 2}^{* *}$ & $\mathbf{0 . 2 1 ^ { * }}$ \\
\hline Period of work experience & $0.16^{*}$ & 0.025 & 0.04 \\
\hline Knowledge & 1 & $\mathbf{0 . 7 8}^{* *}$ & $\mathbf{0 . 4 6}^{* *}$ \\
\hline Attitude & $\mathbf{0 . 7 8}^{* *}$ & 1 & $\mathbf{0 . 3 7}^{* *}$ \\
\hline Practice & $\mathbf{0 . 4 6}^{* *}$ & $\mathbf{0 . 3 7}^{* *}$ & 1 \\
\hline
\end{tabular}

Pearson correlation is used for all, except for educational level spearman correlation

*: Statistically significant at $(\mathrm{p} \leq 0.05) . \quad * *$ : Statistically significant at $(\mathrm{p} \leq 0.01)$.

There was a significant positive moderate correlation between knowledge score and educational levels of food handlers, but the correlation between knowledge score and period of experience is significant positive weak, while no significant difference was found between knowledge score and age. There is a significant positive mild correlation between attitude score and educational level of food handlers, but no significant difference was found regarding age or period of experience. There is a significant strong positive correlation between knowledge and attitude, and moderate positive correlation between knowledge and practice.

\section{Discussion}

It is the responsibility of everyone involved in food serving operations to take into consideration the food's safety and hygiene. Moreover, it is crucial to gain full understanding of the correlation between food safety beliefs, knowledge and hygienic practices to reduce food borne diseases (Zanin et al., 2017). The present study was conducted among all food handlers dealing with food preparation and packing at Mansoura University Hospitals' kitchens during the period from December 2016 to September 2017 to assess their KAP and associated their levels to personal 
and work-related factors. That will motivate the management to offer enough knowledge, training for the attitude and hygienic practice; hence providing higher quality of service.

About half of the contemporary study population showed fair knowledge level. Most of them had good attitude and hygienic practice $(60.7 \%, 59.3 \%$ respectively) (Figure 1). High KAP scores were associated with personal characters being higher among females and university graduates (Table 2). Moreover, the highest KAP scores were noted among veterinarians and cooks (Table 3).

The knowledge of food hygiene and food safety practices of food service staff plays a major role in the incidence of food-borne diseases, which are a widespread public health problem in both developing and developed countries (Mohammad et. al, 2018). In the current study, only one quarter of food handlers had good knowledge (Figure 1). In agreement with this result; Cuprasitrut et al. (2011) found only $13.0 \%$ of food handlers in Thailand had good knowledge, likewise, the percentage was $19.0 \%$ in Vietnam (Vo et al., 2015) and 23\% in Ghana (Kunadu et al., 2016). On the other hand, many studies stated that most food handlers had satisfactory knowledge. The percentage of satisfactory knowledge differ in countries, being $90.0 \%$ in Egypt (Bassyouni et al., 2012), 84.8\% in Jordanian hospitals (Sharif et al., 2013), 83.0\% in Malaysian hospitals (Norhaslinda et al., 2016) and 73.0\% in Brazil (Rebouças et al., 2017). About one quarter of the participants gained low level of education (Table 1), that may explain their poor knowledge level.

Attitude is a necessary mediator between knowledge and practices (Zanin et al., 2017). More than half of the participants showed a good attitude (Figure 1). Similar results were reported by Isara et al. (2013) in Nigeria, Anuradha and Dandekar (2014) in India, and Rebouças et al. (2017) in Brazil. However, the percentage in the current study $(60.7 \%)$ was lower than that reported in previous studies which was; $88.9 \%$ in Jordan (Sharif et al., 2013), 87.2\% in Malaysia (Norhaslinda et al., 2016). On the other hand, it was much higher than the percentage in Thailand (Cuprasitrut et al., 2011) and in Vietnam (Vo et al., 2015) where less than one third of them had good attitude.

In the existing study, the researchers used work observation to capture 
non-verbal occurrences of the food handlers' practice. More than half of the participants had good hygienic practices (Figure 1), in parallel to previous studies in which most of the studied food handlers had good hygienic practices with percentage of $63.5 \%$ in Saudi Arabia (Hamadan and Almhaifer, 2015). On the other hand, many studies stated that most of food handlers had poor hygienic practices. Cuprasitrut et al. (2011) found $15.2 \%$ only of food handlers in Thailand had good practice. Also, Vo et al. (2015) in Vietnam and Kunadu et al. (2016) in Ghana found that $22.3 \%$ and $19 \%$ respectively of food handlers had good practice.

There was a significant positive correlation between practice score and both knowledge and attitude scores in the present study (Table 4). Consistent with Al-Shabib et al. (2016) in Saudi Arabia, Mashuba (2016) in South Africa and Norhaslinda et al. (2016) in Malaysia who reported nearly similar results. These findings contradicted a study in Saudi Arabia which found that good knowledge on food safety didn't necessarily lead to good handling practices (Abdelhafez, 2013). Results of the current study indicated that the food handlers' knowledge level influenced both their attitudes and practices. Safe practice of food handlers in hospitals was an outcome of their intrinsic knowledge and attitude on food safety (Gruenfeldova et al., 2019).

The educational level of food handlers is generally perceived as one of the factors that affect the food safety knowledge and hygiene. In the present study, mean scores of KAP of the food handlers differed significantly regarding educational level, with higher scores in highly educated participants (Table 2); showing positive correlation between education level and KAP scores (Table 4). This result is similar to previous researches by; Sharif et al. (2013) in Jordan and Vo et al., (2015) in Vietnam, but contradict McIntyre et al. (2013) in Canada who claimed that the education level was inversely associated with good practice.

In the present research, there was a highly significant association between KAP scores and type of work of the food handlers with higher average scores among veterinarians and cooks (Table 3). This discrepancy regarding the type of work agrees with the findings of another study in Jordanian hospitals showing higher averages among cooks (Sharif et al., 2013). Also, Bobhate et al. (2011) in India found significant 
association between hygienic practice score and type of work of the food handlers, where the mean score of hygiene among the cooks was higher than that of janitors. It may be attributed to difference in educational level among food handlers.

In the contemporary study, when comparing gender of food handlers (Table 2), higher KAP scores were noted among females more than males. This was consistent with other studies carried out in hospitals in Saudi Arabia (Hamadan and Almhaifer, 2015) and Malaysia (Norhaslinda et al., 2016). However, Kasturwar and Shafee (2011) in India found knowledge among male was higher compared to females. Ercan and Kiziltan (2014) in Turkey didn't find any significant difference regarding gender knowledge.

Training of food handlers in the current study didn't affect neither their knowledge nor attitude (Table 3). This is comparable with the previous reports by; McIntyre et al. (2013) in Canada who found that trained handlers had better scores for practice than those untrained, while Tan et al. (2013) in Malaysia and Mashuba (2016) in South Africa found no significant difference between levels of KAP regarding attendance of training courses. This is contrary to a study by Sharif et al. (2013) who found that all level of KAP was influenced by training of food handlers in Jordanian Military Hospitals.

Work duration was correlated with higher knowledge level and has no significant impact on the overall attitude and practice among the respondents in the present work (Table 4). Ercan and Kiziltan, (2014) in Turkey also reported a similar observation. In contrast, Lee et al. (2017) in Malaysia found that overall food safety KAP scores rise with increasing working duration.

No associations were detected between KAP scores and age in the current study (Table 4). Hamadan and Almhaifer (2015) in Saudi Arabia and Mashuba, (2016) in South Africa also reported a similar observation.

The strength in the existing study appeared using well-validated methods, such as questionnaires for structured interviews, and assessment of practice using observational checklist. Additionally, recruiting all the working food handlers from six university hospitals increased the sample size. On the other hand, study limitation resulted from self-reporting of the participants on knowledge and attitude which may 
underestimate or overestimate data. Hence, future research is suggested to compare KAP pre and post training courses for food safety and hygiene.

Conclusion: Few food handlers were knowledgeable regarding food safety. Practice had a positive correlation with both knowledge and attitude. KAP scores of food handlers differ significantly regarding gender, educational level and type of work. It should be mandatory for food handlers to undergo a supervised food safety training courses prior to renewal of their license to ensure their efficacy.

\section{Conflict of interest}

Authors have declared that no conflict of interest exists.

\section{Funding}

None

\section{References}

1. Abdelhafez A (2013): Knowledge, attitudes, and practices of food service staff about food hygiene in hospitals in makkah area saudi arabia. Life Sci J; 10(3): 1079-85.

2. Al-Shabib NA, Mosilhey SH and Husain FM (2016): Cross-sectional study on food safety knowledge, attitude and practices of male food handlers employed in restaurants of king saud university, saudi arabia. Food Control; 59: 212-7.

3. Anuradha M and Dandekar R (2014):
Knowledge, attitude and practice among food handlers on food borne diseases: A hospital based study in tertiary care hospital. Int $\mathbf{J}$ Biomed Adv Res; 5(04): 196-8.

4. Arendt S, Rajagopal L, Strohbehn C, Stokes N, Meyer J et al. (2013): Reporting of foodborne illness by us consumers and healthcare professionals. Int J Environ Res Public Health; 10(8): 3684-714.

5. Askarian M, Kabir G, Aminbaig M, Memish Z and Jafari P (2004): Knowledge, attitudes, and practices of food service staff regarding food hygiene in Shiraz, Iran. Infect Control Hosp Epidemiol; 25(1): 16-20.

6. Baş M, Ersun AŞ and Kıvanç G (2006) : The evaluation of food hygiene knowledge, attitudes, and practices of food handlers' in food businesses in turkey. Food Control; 17(4) : 317- 22.

7. Bassyouni RH, El-Sherbiny N, Hefzy EH and Wegdan AA (2012): Perception of food safety and prevalence of staphylococcus aureus and salmonella species carriers among fayoum university food handlers. Life Sci J; 9(4): 293440.

8. Bobhate PS, Shrivastava SR and Gupta P (2011): Profile of catering staff at a tertiary care hospital in Mumbai. Australas Med J; 4(3): 148.

9. Codex Alimentarius Commision (2013): Sc5 - hygiene inspection checklist. joint FAO/ WHO food standards programme; food safety authority of Ireland. Available at:https:// www.food.gov.uk/sites/default/files/media/ document/sc5-hygiene-inspection-record.pdf

10. Cuprasitrut $\mathrm{T}$, Srisorrachatr $\mathrm{S}$ and Malai D (2011): Food safety knowledge, attitude and practice of food handlers and microbiological and chemical food quality assessment of food for making merit for monks in Ratchathewi district, Bangkok. Asia Pac J Public Health; 2(1): 27-34. 
11. Ercan A and Kiziltan G (2014): Kitchen safety in hospitals: Practices and knowledge of food handlers in istanbul, turkey. Workplace Health Saf; 62(10): 415- 20.

12. Fadaei A (2015): Assessment of knowledge, attitudes and practices of food workers about food hygiene in Shahrekord restaurants, Iran. World Appl Sci J; 7(33): 1113-7.

13. FDA (Food Drug administration) (2013): Food code: Recommendations of the united states public health service food and drug administration. US Department of Health and Human Services; FDA for Food Safety and applied nutrition. Available at: https://www.fda. gov/food/fda-food-code/food-code-2013

14. Furst AL and Francis MB (2018): Impedancebased detection of bacteria. Chem Rev; 119(1): 700-26.

15. Gruenfeldova J, Domijan $\mathrm{K}$ and Walsh $\mathrm{C}$ (2019): A study of food safety knowledge, practice and training among food handlers in Ireland. Food Control;105 :131- 40.

16. Hamadan HE and Almhaifer AN (2015): Knowledge attitudes and practices of food handlers in hail hospitals. Curr Res Microbiol Biotechnol; 3(1): 573-7.

17. Isara A, Aigbokhaode A, Onwusor V, Onyeulo E and Orumwense S (2013): Food hygiene and safety practices of food service staff in university of benin teaching hospital, benin city, nigeria. Journal of Medicine and Biomedical Research; 12(2): 69-76.

18. Kasturwar N and Shafee M (2011): Knowledge, practices and prevalence of mrsa among food handlers. Int J Biol Med Res; 2(4): 889- 94.

19. Kunadu AP-H, Ofosu DB, Aboagye E and Tano-Debrah K (2016): Food safety knowledge, attitudes and self-reported practices of food handlers in institutional foodservice in Accra, Ghana. Food Control; 69: 324-30.

20. Lazou T, Georgiadis M, Pentieva K, McKevitt A and Iossifidou E (2012): Food safety knowledge and food-handling practices of greek university students: A questionnaire-based survey. Food Control; 28(2): 400-11.

21. Lee HK, Abdul Halim H, Thong KL and Chai LC (2017): Assessment of food safety knowledge, attitude, self-reported practices, and microbiological hand hygiene of food handlers. Int J Environ Res Public Health;14(1): 55.

22. McIntyre L, Vallaster L, Wilcott L, Henderson SB and Kosatsky T (2013): Evaluation of food safety knowledge, attitudes and self-reported hand washing practices in foodsafe trained and untrained food handlers in british columbia, canada. Food Control; 30(1): 150-6.

23. Mohammad AM, Chowdhury T, Biswas B and Absar N( 2018): Food poisoning and intoxication: a global leading concern for human health . In book: Food Safety and Preservation (Chapter: 11).Publisher: Elsevier: 307-52 . Academic Press . DOI: 10.1016/B978-0-12814956-0.00011-1

24. Niles NJ (2019): Basics of the US health care system. Jones \& Bartlett Learning. Available at : http://samples.jbpub.com/9781284102888/ FontMatter.pdf

25. Norhaslinda AHN and Khalili MA (2016): Knowledge, attitudes and practices (kap) on good manufacturing practices (gmp) among food handlers in terengganu hospitals. Int $\mathbf{J}$ Pharm Pharm Sci; 8(11).

26. Rebouças LT, Santiago LB, Martins LS, Menezes ACR, Araújo MdPN et al. (2017): Food safety knowledge and practices of food handlers, head chefs and managers in hotels' restaurants of salvador, brazil. Food Control; 73: 372-81.

27. Rohin $\mathrm{N}$ and Khalilir MA (2016): Knowledge, attitudes and practices (kap) on good manufacturing practices (gmp) among food handlers in terengganu hospitals. Int J Pharm Pharm Sci; 8(11): 53- 9.

28. Sharif L, Obaidat MM and Al-Dalalah M-R 
(2013): Food hygiene knowledge, attitudes and practices of the food handlers in the military hospitals. Food Nutr Sci; 4(03): 245.

29. Thelwell-Reid M (2014): Food safety knowledge and self-reported practices of food handlers in jamaica. Doctoral dissertation, Walden University. Available at : https:// scholarworks.waldenu.edu/cgi/viewcontent.cgi ?article $=1074 \&=\&$ context $=$ dissertations

30. Tokuç B, Ekuklu G, Berberoğlu U, Bilge E and Dedeler H (2009): Knowledge, attitudes and self-reported practices of food service staff regarding food hygiene in edirne, turkey. Food Control; 20(6): 565-8.
31. Vo TH, Le NH, Le ATN, Minh NNT and Nuorti JP (2015): Knowledge, attitudes, practices and training needs of food-handlers in large canteens in southern vietnam. Food Control; 57: 190-4.

32. Young I, Greig J, Wilhelm BJ and Waddell LA (2019): Effectiveness of food handler training and education interventions: A systematic review and meta-analysis. J Food Prot; 82(10): 1714- 28.

33. Zanin LM, da Cunha DT, de Rosso VV, Capriles VD and Stedefeldt E (2017): Knowledge, attitudes and practices of food handlers in food safety: An integrative review. Food Res Int; 100: 53-62. 
